\title{
Measurement of patients' knowledge of their medication in community pharmacies in Portugal
}

Joaquín Salmerón Rubio ${ }^{1}$

Pilar García-Delgado ${ }^{1}$

Paula Iglésias-Ferreira ${ }^{2}$

Henrique Mateus-Santos ${ }^{3}$

Fernando Martínez-Martínez ${ }^{1}$

${ }^{1}$ Grupo de Investigación en Atención Farmacéutica, Facultad de Farmacia, Universidad de Granada. Calle Real de Cartuja 36. 18012 Granada España. farjoaquin@gmail.com ${ }^{2}$ Grupo de Investigação em Cuidados Farmacêuticos, Universidade Lusófona de Humanidades e Tecnologias. ${ }^{3}$ Instituto Pharmcare.

\begin{abstract}
The scope of this article is to determine patients' knowledge about the medication they take. For this purpose, a cross-sectional, observational and descriptive study was conducted. Knowledge was measured by a valid and reliable questionnaire (CPM-PT-PT), given to the patients attending community pharmacies participating in the study, who had prescriptions for one or more drugs in the Lisbon Metropolitan Area. Knowledge was assessed in four dimensions: therapeutic objective, process of use, safety and maintenance of the medications that the patient takes. Thirty-five pharmacies participated, and $633 \mathrm{val}$ id patients were obtained. Fully $82.5 \%$ (95\% CI: $79.3 \%-85.3 \%)$ were uninformed about the nature of the drug they use. In all items, there was a high percentage of patients with incorrect knowledge, with emphasis on precautions (44.7\%). The dimension that the patients were least aware of was "drug safety" (1.9\%). Eight out of 10 patients in the population do not know what drug they use. The highest lack of correct information was with respect to the "safety" of the medication.
\end{abstract}

Key words Questionnaires, Patient, Medication, Knowledge 


\section{Introduction}

Patients' insufficient or wrong knowledge regarding the medication they use may vary and probably lead to the incorrect use of the latter, thus causing a decrease in its efficacy, or the appearance of other health problems. The prevalence of negative results associated to medication (NRM) is so high that it is deemed an important public health problem ${ }^{1-4}$. A basic pillar to facilitate obtaining excellent results in pharmacotherapy lies in adequate knowledge of patients regarding their own pharmacological treatment. Because of this, patients' knowledge on their medication (PKM) is a key part to minimize the appearance of NRM. Although PKM is a term used frequently in health sciences, most of the studies found measure PKM without having a clear definition of this variable. García-Delgado et al. define PKM as "The set of information acquired by the patient on his/her medication, needed for the correct use of the latter, and which includes the therapeutic goal (indication and efficacy), the process for use (posology, regimen, means of administration and treatment duration), safety (adverse effects, precautions, contraindications and interactions) and its conservation "5.

There is not much data published on patients knowledge of their medication, and, the few studies found measure concrete aspects of knowledge and/or specific therapeutic groups, without counting upon a valid tool for this. Despite this, all of the results point to a lack of knowledge of patients when it comes to their pharmacological treatments ${ }^{6-20}$.

At present, the only validated questionnaire that has been found to measure PKM in a general way, that is, that could be applied to a patient undergoing treatment with any type of medication and with any type of pathology, is the one validated by García-Delgado et al. ${ }^{5}$.

To evaluate which sanitary interventions are necessary in Portugal, it is necessary to determine if there really does exist a lack of information regarding medication at large. If this holds true, discover concrete cases of this lack of information, identify the degree of knowledge of Portuguese patients, and if it suffices, verify the correct process in the use of the medication. This would help justify the use of means and personnel in sanitary education programs that are more adequate, to cover the true needs of patients in Portugal and facilitate an enhancement in this clinical practice.

\section{Objective}

Determine the knowledge of patients, users of the community pharmacies belonging to the Metropolitan Area of Lisbon, regarding their medication, including the degree of global knowledge, by dimensions and items.

\section{Methods}

A descriptive crosscut (transversal) study carried out in volunteer community pharmacies started in December of 2009 and extended until January of 2010, in a convenience sampling for patients who resort to these community pharmacies on the Greater Lisbon Metropolitan Area. The population were all users of medication or caregivers who resorted to community pharmacies to pick up one or more medications, with or without prescriptions. Patients with difficulties in communication and those referred from other services aware of the pharmacy and those who had already participated in the study were excluded.

To determine the degree of patients' knowledge regarding their medication, the transcultural adaptation to European Portuguese was used for questionnaire PKM-PT-PT ${ }^{21}$, which showed its validity and reliability in a prior study on the psychometric properties of the adapted questionnaire ${ }^{22}$. Interviewers and evaluators were always pharmacists trained for this specific purpose. The PKM of a medication was evaluated per patient. If the patient requested more than one medication, the pharmacist selected one of them randomly. The pharmacist who did the evaluation had also carried out the interview.

This was done by allocating a score to each of the patient's responses, based on the degree of agreement between the information given by the patient and the reference information (medical prescription or, when not available, the Summary of Characteristics of Medications (SMC from Infarmed-the National Authority on Medication and Health Products I.P):

- Incorrect: Score-1 (The information that patient has does not match the reference information);

. Does not know: Score 0 (The patient verbally indicates lack of knowledge);

. Insufficient: Score 1 (The patient's answer is not complete, does not guarantee the patient has the necessary information to warrant the correct use of the medication); 
- Correct: Score 2 (The patient's information is in accordance to the reference information). For this purpose, each patient obtained a score between -1 to 2 , for each question in the PKM questionnaire. To calculate final total knowledge about the medication (PKM), each receives a different score based on the dimension it belongs to, applying the following formula obtained from the prioritization set forth by the expert panel in the design phase of the original questionnaire, and the dimensions extracted from statistics $(\mathrm{AFCP})^{21,22}$ :

$\mathrm{PMK}=\frac{\left[1.2 \Sigma \mathrm{P}_{\mathrm{i}}^{\mathrm{A}}\right]+\left[1.1 \Sigma \mathrm{P}_{\mathrm{i}}^{\mathrm{B}}\right]+\left[0.85 \Sigma \mathrm{P}_{\mathrm{i}}^{\mathrm{C}}\right]+\left[0.6 \Sigma \mathrm{P}_{\mathrm{i}}^{\mathrm{D}}\right]}{(1.2 \mathrm{x} 4)+(1.1 \mathrm{x} 2)+(0.85 \mathrm{x} 4)+(0.6)}$

${ }^{*} \mathrm{Pi}^{\mathrm{X}}=$ Score obtained by the patient for each question from each dimension $\mathrm{X}$. Where:

- Process for use: Posology (question 2); Regimen (question 3); Treatment duration (question 4); Form of administration (question 5);

- Therapeutic goal: Indication (question 1); Efficacy (question 9);

- Safety: Precautions (question 6); Adverse effects (question 7); Contraindications (question 8); Interactions (question 10);

- Conservation: Conservation (question 11). The maximum score is 2 and the minimum 0 . The minimum criteria set forth for knowledge ( 2 points) are the first five questions. If the partial score of one of them is lower than 2 , it is deemed that the patient did not have the necessary information to ensure the correct process of use of the medication $(\mathrm{PKM}=0)$ Knowledge of the medication was classified in:

- Does not know medication: 0 points.

- Insufficient knowledge: From 0.60 to 1.26.

- Sufficient knowledge: From 1.27 to 1.60.

- Optimal knowledge: From 1.61 to 2. This variable is reclassified in:

- Does not know the medication that encompasses the categories or does not know and insufficient knowledge.

- Knows the medication which encompasses the categories of sufficient and optimal knowledge. Thirteen (13) independent variables were recompiled referring to the study pharmacy, the patient and the medication. There was a calculation of the sampling size needed to estimate the percentage of patients who had no knowledge regarding the medication of $50 \%$ (based on the results of the pilot study), with a maximum admissible error of $\pm 4 \%$ and a confidence level of 95\%. 598 patients were necessary for the Greater Lisbon Area ${ }^{23}$.

Screening of the sampling subjects was done through a systematic sampling at each pharmacy, collecting information from the 20 patients serviced throughout the day, in a day chosen randomly, based on a sampling spreadsheet. Thirty (30) pharmacies had to participate. To be able to encode and define the variables, to calculate the aggregated variables and for statistical analysis, the SPSS statistical package was used 17.0.

For allocation to therapeutic groups, according to the anatomic-therapeutic classification of specialties, ATC level 1, ATC level 2, ATC level 4, the information collected in the updated RCM was used, approved by Infarmed for Portugal. The variables for the pharmaceutical form were also recoded and the means of administration based on the ATC data, as well as the information collected at Infomed.

A uni-variant descriptive analysis was carried out, showing the frequency of appearance of the different variables in the study population, as well as the losses produced during field work. For the qualitative variables, absolute and relative tables were obtained, and for the quantitative ones, core trend measurements (mean), dispersion measures (standard deviation) and position measurements (quartiles). Population estimates for the prevalence of patients' knowledge on the medication were calculated, including their corresponding errors in sampling for the confidence intervals.

\section{Results}

Thirty five (35) community pharmacies from the Greater Lisbon Area took part in the study, distributed as follows: Amadora (4), Cascais (2), Lisboa (12), Odivelas (4), Oeiras (2), Sintra (8), Vila Franca de Xira (3), which screened 633 patients, with a rate of response of $90.4 \%$. From the 700 initial patients, 12 refused the invitation to participate in the study, and from the 688 chosen for evaluation, 36 did not accept to continue and participate and 19 questionnaires had no reading, 6 were not finished. The type of pharmacy most represented was that of "urban pharmacies" (24 of 35) that serviced a population of "middle" social economic brackets.

In Table 1 there is a description of the study population, based on the patients' own charac- 
teristics, highlighting that $61.9 \%$ were women. $85 \%$ acquired the medication for their personal use. The average age was of 56 years $(\mathrm{DE}=17.1)$.

Only $10 \%$ were foreigners and more than half carried out paid labor (52.3\%). Most of the patients had basic education, albeit a significant percentage $(18.7 \%)$ had received higher education. When it comes to the description of the sample, based on the characteristics of the medication itself: $25 \%$ of patients stated that they were not

Table 1. Description of the study population based on patient characteristics and characteristics of the medication itself.

\begin{tabular}{|c|c|c|}
\hline Variables & $\begin{array}{l}\text { Frequency } \\
n=633\end{array}$ & $(\%)$ \\
\hline Age (mean/SD) & $(56 / 17,1)$ & \\
\hline \multicolumn{3}{|l|}{ Gender } \\
\hline Female & 392 & $(61.9)$ \\
\hline Male & 241 & $(38.1)$ \\
\hline \multicolumn{3}{|l|}{ Country of Origin } \\
\hline Portugal & 570 & $(90.0)$ \\
\hline Foreign & 63 & $(10.0)$ \\
\hline \multicolumn{3}{|l|}{ Education Level } \\
\hline No studies & 45 & $(7.1)$ \\
\hline Primary & 338 & $(53.5)$ \\
\hline Secondary & 131 & $(20.7)$ \\
\hline University & 118 & $(18.7)$ \\
\hline \multicolumn{3}{|l|}{ Type of Employment } \\
\hline Housewives/retired/strike & 331 & $(52.3)$ \\
\hline Non-qualified manual labor & 48 & $(7.6)$ \\
\hline Qualified manual labor & 60 & $(9.5)$ \\
\hline Administrative and merchants & 120 & $(19.0)$ \\
\hline University students & 50 & $(7.9)$ \\
\hline Leaders and entrepreneurs & 24 & (3.8) \\
\hline \multicolumn{3}{|l|}{ Concern about health problems } \\
\hline Scant & 159 & $(25.1)$ \\
\hline Regular & 206 & $(32.5)$ \\
\hline Enough & 268 & $(42.3)$ \\
\hline \multicolumn{3}{|l|}{ Number of Medications } \\
\hline Monotherapy & 140 & $22.2 \%$ \\
\hline 2 to 4 & 266 & $42.1 \%$ \\
\hline Polymedication $(\geq 5)$ & 226 & $35.8 \%$ \\
\hline \multicolumn{3}{|l|}{ Time of use of the medication } \\
\hline Beginning of treatment & 163 & $25.8 \%$ \\
\hline 0.5 to 6 months & 106 & $16.8 \%$ \\
\hline 7 to 12 months & 57 & $9.0 \%$ \\
\hline 13 to 24 months & 69 & $10.9 \%$ \\
\hline$>24$ months & 237 & $37.5 \%$ \\
\hline \multicolumn{3}{|c|}{ User (the person who requests the medication) } \\
\hline Own use & 537 & $84.8 \%$ \\
\hline Care giver & 96 & $15.2 \%$ \\
\hline \multicolumn{3}{|l|}{ Prescriber } \\
\hline Physician & 547 & $86.4 \%$ \\
\hline Pharmacist & 29 & $4.6 \%$ \\
\hline Self- medication & 57 & $9.0 \%$ \\
\hline
\end{tabular}

concerned about their health problem, while those with great concern regarding their health problem represented $42.3 \%$. $22 \%$ of the participants used a single medication, compared to $36 \%$ of patients that were poly-medicated. A high percentage of patients $(78 \%)$ knew the name of the medication they were taking. $86 \%$ of the drugs studied had been prescribed by a physician, $5 \%$ recommended by a pharmacist, and $9 \%$ referred to self-medication.

Twenty six percent $(26 \%)$ of the medication requested was to initiate the treatment. The therapeutic group most used was " $\mathrm{C}$ : Cardiovascular apparatus" with $24.6 \%$, followed by $21.5 \%$ of medication belonging to the "N: Nervous System" and group "A: Digestive tract and metabolism with $12.9 \%$.

Graph 1 shows the patients' global knowledge regarding their medication, highlighting that $82.5 \%$ (IC95\%: 79.3\%-85.3\%) do not know the medication they use.

When it comes to the PKM distribution by dimensions, the one which presented a greater percentage of knowledge was "therapeutic goal" (70.9\%), followed by "process of use" with 36.7\%, being that the dimensions of "safety" and conservation" were the ones presenting the lower level of knowledge, with $1.9 \%$ and $5.8 \%$ respectively. Table 2 shows the distribution on the degree of knowledge in the study population, for each of the PKM items. It is worthwhile pointing out that the percentage of patients with incorrect information for each of the knowledge items goes beyond $18 \%$, except for the precautions with the medication, which is the indicator with the greatest incorrect information accumulated (44.7\%).

The percentage of patients that knew the medication was of $17.5 \%$, corresponding to $15.1 \%$ of sufficient knowledge and a $2.4 \%$ of optimal knowledge. Of the $82.5 \%$ that does not know the medication (IC95\%: 79,3\%-85,3\%), $16.6 \%$ had insufficient knowledge and $65.9 \%$ had none at all, or which is the same, 4 out of every 5 patients do not know the medication they use (Graph 1).

The dimension that presents the best knowledge was "therapeutic goal", with 70.9\% ( $\mathrm{p}<$ $0,001)$, followed by "process of use" with 36.7\% $(\mathrm{p}=0,032)$, with the dimensions of "safety" and "conservation" as those with the lowest levels of knowledge, with $1.9 \%$ and 5.8\% respectively. Knowledge of the medication reached percentages higher than $70 \%$ in the items of indication $(89 \%)$, posology, regime, means of administration and efficacy. Notwithstanding this, knowl- 


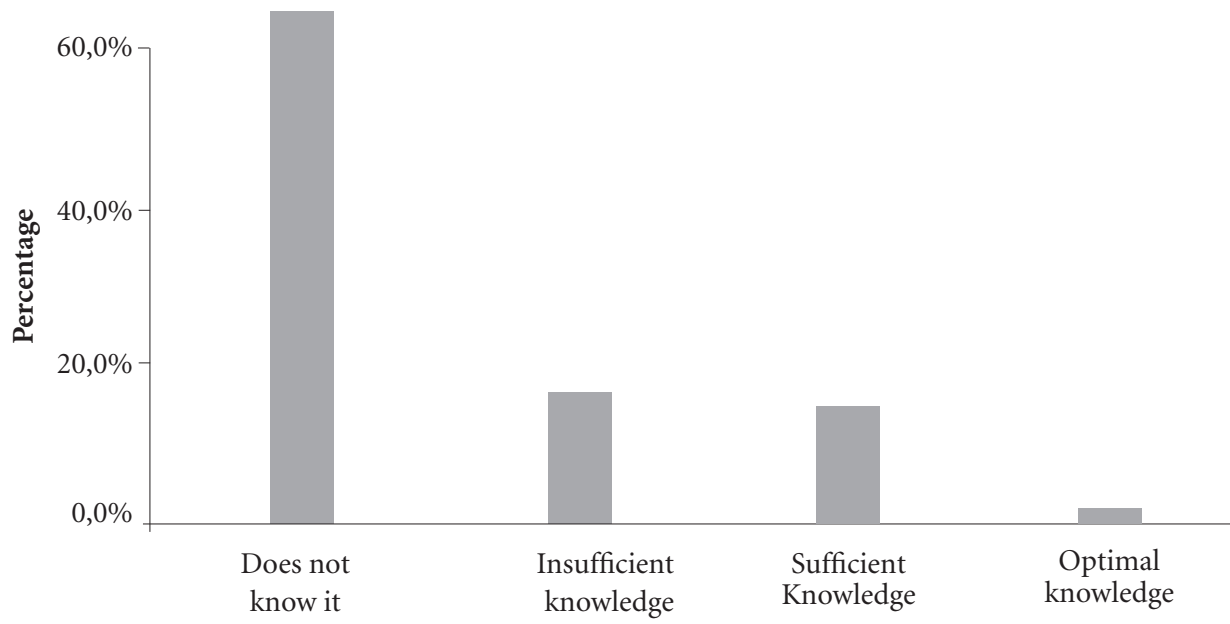

Classification of total knowledge of the drug (4 categories)

Graph 1. Distribution of the degree of global knowledge of the study population.

Table 2. Distribution of the degree of knowledge of the study population for each of the PKM items.

\begin{tabular}{lrrrr}
\hline \multicolumn{1}{c}{ Items } & Incorrect Knowledge & Does not know it & Insufficient knowledge & Knows it \\
\hline Indication & $39(6.2 \%)$ & $20(3.2 \%)$ & $12(1.9 \%)$ & $562(88.8 \%)$ \\
Dosage & $77(12.2 \%)$ & $30(4.7 \%)$ & $32(5.1 \%)$ & $494(78.0 \%)$ \\
Regimen & $82(13.0 \%)$ & $28(4.4 \%)$ & $42(6.6 \%)$ & $481(76.0 \%)$ \\
Treatment duration & $59(9.3 \%)$ & $178(28.1 \%)$ & $13(2.1 \%)$ & $383(60.5 \%)$ \\
Form of administration & $67(10.6 \%)$ & $36(5.7 \%)$ & $62(9.8 \%)$ & $468(73.9 \%)$ \\
Precautions & $283(44.7 \%)$ & $219(34.6 \%)$ & $59(9.3 \%)$ & $72(11.4 \%)$ \\
Adverse effects & $77(12.2 \%)$ & $466(73.6 \%)$ & $44(7.0 \%)$ & $46(7.3 \%)$ \\
Contraindications & $95(15.0 \%)$ & $460(72.7 \%)$ & $58(9.2 \%)$ & $20(3.2 \%)$ \\
Effectiveness & $38(6.0 \%)$ & $112(17.7 \%)$ & $26(4.1 \%)$ & $457(72.2 \%)$ \\
Interactions & $110(17.4 \%)$ & $407(64.3 \%)$ & $68(10.7 \%)$ & $48(7.6 \%)$ \\
Conservation & $87(13.7 \%)$ & $90(14.2 \%)$ & $419(66.2 \%)$ & $37(5.8 \%)$
\end{tabular}

edge of the contraindications reached a mere $3 \%$, conservation $6 \%$ and adverse effects and contraindications about $7 \%{ }^{2}$.

The greatest percentages of knowledge we attained in the items that refer to the therapeutic goal and the process of use, and the lowest were those referring to safety and conservation (Graph 2). The percentage of patients with incorrect information for each of the knowledge items is not greater than $18 \%$, except for the precautions with the medication, which is the indicator with the greatest accrued information (44.7\%).
The percentages of no knowledge stood out in the items that refer to medication safety, and were the lowest in those referring to the therapeutic goal and process of use.

The form of conservation ended up being the item with the greatest percentage of insufficient knowledge.

Percentages greater than $70 \%$ were found for the items of indication, posology, regimen, form of administration and efficacy. However, the percentage did not reach $10 \%$ in those referring to safety and conservation (Graph 2). 


\section{Discussion}

There has not been much data published on PKM. The studies found, despite using different methods, reveal a lack of PKM similar to the results found in the present study; over half of the patients studied do not know the medication they use. Some locate the prevalence of knowledge between $17 \%$ and $29.4 \% \%^{9,15,24}$, other studies obtain higher results and locate prevalence of the necessary knowledge for correct use between $42.5 \%$ and $57 \%^{10,11,16}$. Domecq and Belmar Herrera $^{9}$ state that only $29.4 \%$ of patients have an acceptable degree of knowledge. Etges Fröhlich et al. ${ }^{10}$, set forth that $42.5 \%$ have "regular" knowledge and that $46.3 \%$ "insufficient" and the rest null. For Silva and Mangue ${ }^{16}, 57 \%$ of outpatient patients from a region in Brazil have "regular" knowledge of the medication they take. Perera et al. ${ }^{24}$, refer to good knowledge of the medication prescribed in $17.5 \%$, insufficient in $36 \%$ and poor in $46 \%$. Menolli et al. ${ }^{11}$, state that only $46.6 \%$ of patients have the necessary information to correctly use their medication. Altimiras et al. ${ }^{15}$, in a study at the hospital San Pau in Barcelona conclude that there is very little knowledge regarding medication, only $17 \%$ know their medication. According to the only study found that uses a method of valid and reliable measures,
66\% (IC95\%: 63.3\%-68.7\%) of the patients do not know the medication they use $e^{5,25}$.

Several biases that could affect the internal validity of the study were encountered. One of them could be the degree of voluntariness of pharmacists to participate in the study, and this could limit how representative the sampling is. However, the unit of analysis were the patients, a reason why it is indispensable to study the influence that the location of the pharmacy may have on the patients' knowledge. As results show, the pharmacies that participated did not have the correct profile to distinguish them from the rest of the pharmacies that did not take part in the study.

The researching team was aware that a negative response could introduce a bias in screening, given that a group of the population with similar characteristics could refuse to participate, all pointing towards a similar profile of knowledge. Nevertheless, a $91.7 \%$ rate of response was obtained, and only a small percentage refused to take part in the study, that is, 58 of 700 , which did not make it possible to carry out the statistical analysis of non-response.

On the other hand, the erroneous or incomplete filling-in of the knowledge items conditioned this to having to exclude this information in the study, with the possibility of leading to a bias in classification. However, in this study,

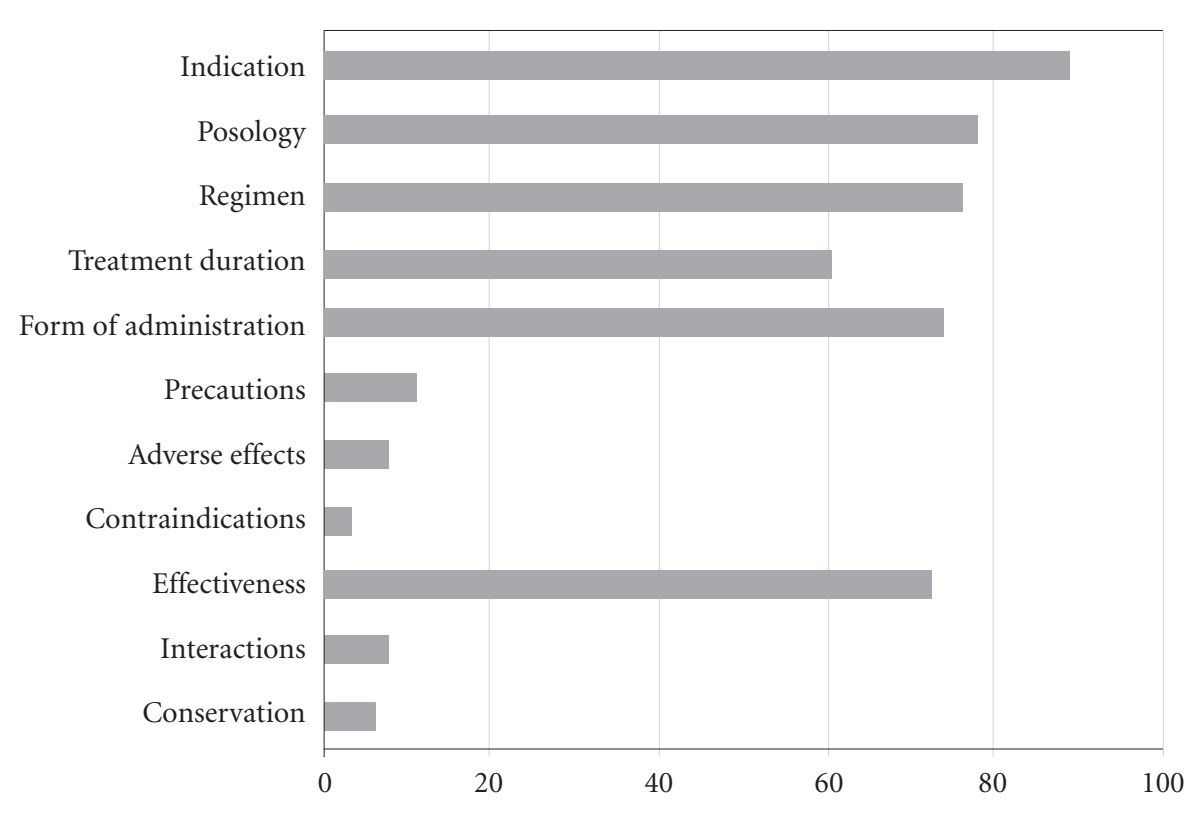

Graph 2. Distribution of patients that know each of the different items of the medication. 
the frequency of erroneous filling was (1.28\%), which could make it possible to state that the results obtained are not biased due to this limitation. We contemplated the possibility that the choice of the study medication could also represent a screening bias, overestimating the results obtained. To minimize that possibility, when the patient had several medications, the medication used for the measurement ended up being chosen randomly.

There was the possibility that, as there were 35 different interviewers, the interviewers bias would also appear. This was minimized with specific training for the latter. On the other hand, evaluation could introduce a bias in classification, which we attempted to dilute with the specific training of the 4 evaluating pharmacists, who independently evaluated all of the questionnaires.

he investigator team once again evaluated the pharmacists, specially emphasizing the discrepancies in classification among the 4 evaluators. Analyzing the results obtained, and after the evaluation of the biases in screening, classification and confusion, it can be stated that the sample selected adequately presents the total of the study population: users of community pharmacies located in the Greater Lisbon Area.

Due to the fact that in the present study the PKM was measured with the transcultural adaptation into Portuguese (European) ${ }^{21}$, and subsequent validation $^{22}$ of the only generic and validated questionnaire that has been found, what will preferably be compared is the prevalence results in both studies (original questionnaire measured in the provinces in Spain and adaptation and re-validation applied in Portugal).

The prevalence of lack of knowledge (category "does not know") is identical in Spain and Portugal, with a value of $65.9 \%$ in Portugal, compared to 66\% in Spain. In Spain, the category "insufficient knowledge" was not represented, while it was in Portugal, with $16.6 \%$. Because of this, when reclassifying this variable, the percentage of lack of knowledge in Portugal increases.

It is very important to highlight that in both studies, the safety dimension is the least known $(4.4 \%)$ in Spain and $(1.9 \%)$ in Portugal. This implies that patients ignore what it is the medication could cause and how to prevent safety problems. This lack of knowledge could give place to a greater risk of non-compliance, and even to untreated health problems, with the consequent health expenses associated to this. Few studies have differentiated the knowledge regarding concrete aspects of the medication, de- spite this; they coincide with the results of this study ${ }^{6-11,13-16,24}$.

Based on the results of the correct information for each item, we can deduce that patients know some of the minimum criteria of PKM, but not all. Because of this, despite the fact the percentage of knowledge of items 1 to 5 ranges from $60.5 \%$ to $88.8 \%$ do not know everything they need to know to adequately use the medication (have a partial score of 2 points in all of these). The dimension with the greatest knowledge is "Therapeutic goal" $70.9 \%$, a reason why many of the Portuguese know "what the medication is for" and "what they should expect" from it. Nevertheless, the knowledge of the "Process of use" is much lower, at $36.7 \%$ in Portugal. This leads us to think that the majority of patients know about different points in the medication, but do not know everything that is necessary to use it correctly. This is extremely relevant, as there was a high percentage of patients who consume medication and have no information whatsoever to warrant a rational use of the latter. With the use of the PKM-PT-PT questionnaire in pharmaceutical practice, it will be possible to identify these patients, and apply strategies to minimize the problem.

The fact that only $5.8 \%$ of the Portuguese patients have no knowledge about the adequate conservation of their medication reveals that there could exists the risk that patients are consuming poorly preserved medication, with the potential problem of hazards in the public health system entailed by this. Not all of the studies found measure the patients' knowledge regarding all of the items of the PKM. In Table 3, there is a comparison, by indicator, of the results of this study and the data available in the literature consulted.

The percentages of knowledge obtained in this study are similar to that of others, albeit in the majority of aspects, our results fall within the higher ranges. This could be explained because of the differences in the characteristics of the population studied, and/or the PKM measurement methods. Practically all of the studies measure knowledge regarding the name of the medication, concluding that over $60 \%$ of patients have knowledge of that $^{5,12,14,16,24,26}$.

The result of the patient's knowledge on the administration regimen for the medication obtained in this study is located in the percentage interval given by other authors, between $70 \%$ and $90 \% 0^{5,10,16,24,26}$. It seems logical that the regimen be one of the aspects of the medication that most awakens patients' interest, and as such, be 


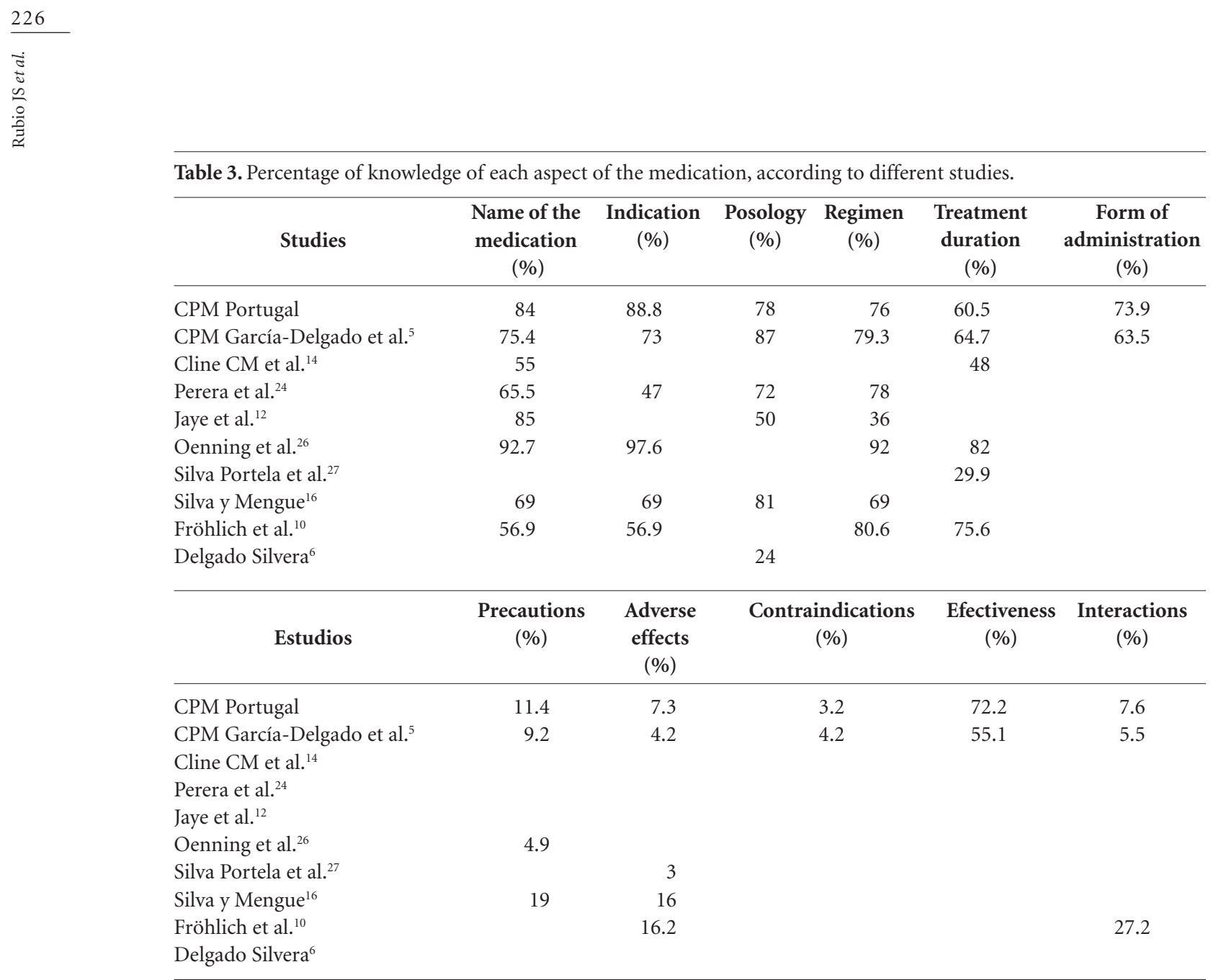

the most known, given that it implies a direct action; taking the medication at a given time.

Knowledge of the indication, posology and the duration of treatment have also been studied by other authors, with the conclusion that there is a range of correct information for these indicators of about $60 \%$ to $80 \%$, $10,16,24,26$, excluding some results that are higher in indication ${ }^{26}$ or lower in indication ${ }^{24}$, in posology $y^{6,12}$, in treatment duration ${ }^{14,27}$. The results of this study for posology and treatment duration fall within the interval. Despite this, the percentage of knowledge of indication is the highest, close to $90 \%$. This difference may be due to the lower mean age in our study population, a group that grants a great deal of importance to knowing why they have to take the medication.

Items with the lowest degree of knowledge observed in the study population were those referring to contraindications, adverse effects, interactions and precautions, data that is supported by several published results , $, 6,16,26,27$.
Definitely, the dimension "Process of use" is known by only $36.7 \%$ in the Portuguese population, which points to the fact that there is a percentage of patients who lack the necessary information to ensure they are using the medication correctly. This means that over $60 \%$ of the population is at risk of suffering a NRM due to lack of the necessary information to adequately use medication. On the other hand, the extremely high percentage of lack of knowledge of the "safety" dimension $(98.1 \%)$ points to the need of setting forth strategies to inform patients, as part of the lines of activity in health policies aimed at increasing the safe use of medication among the Portuguese population.

Based on all of the results obtained, it is worthwhile pointing out that patients know more the name of the medication, than the medication per se, and that what is definitely lacking are those aspects that relate to safety and the necessary information to carry out the correct use of the medication. 


\section{Conclusions}

The results obtained show a very high lack of knowledge among patients regarding the medication they use, despite the numerous sanitary strategies adopted. The use of this questionnaire to measure PKM-PT-PT, valid and reliable, could be incorporated by pharmacies in their daily practice, and as part of the services they offer, to help patients understand the correct process of use of their own medication, thus, thus ensuring positive clinical results will be attained.

\section{Collaborations}

J Salmerón Rubio has worked in the design, research and methodology, P Iglésias-Ferreira in the design, research methodology and statistics, P García-Delgado at conception, research methodology and statistics, $\mathrm{H}$ Mateus-Santos in research, writing and methodology, F Martínez-Martínez at conception and methodology. 


\section{References}

1. Johnson JA, Bootman JL. Drug-related morbidity and mortality. A cost-of-illness Model. Arch Intern Med 1995; 155(18):1949-1956.

2. Ernst FR, Grizzle AJ. Drug-related morbidity and mortality: updating the cost-of-illness model. J Am Pharm Assoc 2001; 41(2):192-199.

3. Climente M, Quintana I, Martinez G, Atienza A, Jiménez NV. Prevalencia y características de la morbilidad relacionada con los medicamentos como causa de ingreso hospitalario. Aten Farm 2001; 3(1):9-22.

4. MI, Faus MJ, Fajardo PC, Luque FM, Sierra F, Martinez-Olmos J, Cabrera A, Fernandez-Llimos F, Martinez-Martinez F, Jiménez J, Zarzuelo A. Medicine-related problems resulting in emergency department visits. Eur J Clin Pharmacol 2006; 62(5):387-393.

5. García-Delgado P, Gastelurrutia MA, Baena MI, Fisac F, Martínez-Martínez F. Validación de un cuestionario para medir el conocimiento de los pacientes sobre sus medicamentos. Aten Primaria 2009; 41(12):661-669.

6. Delgado Silvera E. Información de medicamentos al paciente anciano [tesis]: Universidad Complutense de Madrid; 1999.

7. O’Neil CK, Poirer TI. Impact of patient knowledge, patient-pharmacist relationship, and drug perceptions on adverse drug therapy outcomes. Pharmacotherapy 1998; 18(2):333-340.

8. Akici A, Kalaça S, Uğurlu MU, Toklu HZ, Iskender E, Oktay S. Patient knowledge about drugs prescribed at primary healthcare facilities. Pharmacoepidemiol Drug Saf 2004; 13(12):871-876.

9. Domecq Jeldres C, Belmar Herrera A. Atención primaria de salud: perfil de uso de los medicamentos en adultos mayores. Acta Farmacéutica Bonaerense 1999; 14(2).

10. Fröhlich SE, Silva T, Dal-Pizzol F, Sotero Serrante M. Instrumento para avaliação do nível de conhecimiento da prescrição na atenção primária. Rev Saude Publica 2010; 44(6):1046-1054.

11. Menolli PVS, Ivama AM, Cordoni Junior L. Caracterización de los servicios farmacéuticos de atención primaria del Sistema Único de Salud en Londrina, Paraná, Brasil Rev Panam Salud Publica 2009; 25(3):254-259.

12. Jaye C, Hope J, Martin JR. What do general practice patients know about their prescription medications? $N Z$ Med J 2002; 115(1162):U183.

13. Cyr JG, McLean W. Patient knowledge of prescription medication: present lack-future necessity. Can Pharm J 1978; 17:361-367.

14. Cline CMJ, Björck-Linné AK, Israelsson BY, Willenheimer RB, Erhardt LR. Erhardt. Non-compliance and knowledge of prescribed medication in elderly patients with heart failure. Eur J Heart Fail 1999; 1(2):145-149.

15. Altimiras J, Bassons I, Gelonch A, Selva C. Evaluación del conocimiento de los pacientes crónicos sobre su tratamiento. Farm Clin 1987; 4(2):150-158.

16. Silva TSE, Mengue SS. Nivel de informação respeito de medicamentos prescritos a pacientes ambulatoriais de hospital universitário. Cad Saude Publica 2000; 16(2):449-455.
17. Eric Edward BS, Amy Pasanen AA. Evaluation of Knowledge and Medication Use in Patients in Rural Clinics. [cited 2008 Sept 20]. Available from: http:// ahec.health.ufl.edu/chs/2003/Edwards.pdf.

18. Huang YM, Wang HP, Yang YH, Lin SJ, Lin HW, Chen CS, Wu FL. Effects of a national health education program on the medication knowledge of the public in Taiwan. Ann Pharmacother 2006; 40(1):102-108.

19. Hughes L, Wittlesea C, Luscombe D. Patients' knowledge and perceptions of the side-effects of OTC medication. J Clin Pharm Ther 2002; 27(4):243-248.

20. Boonstra E, Lindbaek M, Ngome E, Tshukudu K, Fugelli P. Labelling and patient knowledge of dispensed drugs as quality indicators in primary care in Botswana. Qual Saf Health Care 2003; 12(3):168-175.

21. Salmerón-Rubio J, Iglésias-Ferreira P, Delgado PG, Mateus-Santos H, Martínez-Martínez F. Adaptação intercultural para português europeu do questionário "Conocimiento del Paciente sobre sus Medicamentos" (CPM-ES-ES). Cien Saude Colet 2013; 18(12):36333644.

22. Salmerón-Rubio J, Iglésias-Ferreira P, Delgado PG, Mateus-Santos H, Martínez-Martínez F. Validación del cuestionario de medida del conocimiento del paciente sobre su medicamento adaptado al portugués. Cien Saude Colet 2011; 19(4):1141-1150.

23. Portugal. Instituto Nacional de Estatística. Retrato Territorial de Portugal 2009. Lisboa: Instituto Nacional de Estatística; 2011.

24. Perera T, Ranasinghe P, Perera U, Perera S, Adikari M, Jayasinghe S, Constantine GR. Knowledge of prescribed medication information among patients with limited English proficiency in Sri Lanka. BMC Reseach Notes 2012; 5:658.

25. Delgado PG. Conocimiento del paciente sobre sus medicamentos [tese]. Granada: Universidade de Granada; 2008.

26. Oenning D, de Oliveira BV, Blatt CR. Conhecimento dos pacientes sobre os medicamentos prescritos após consulta médica e dispensação. Cien Saude Colet 2011; 16(7):3277-3283.

27. Silva Portela A, Silva Simões MO, Fook SML, Neto ANM, Silva PCD, Oliveira BH. Prescrição médica: orientações adequadas para o uso de medicamentos? Cien Saude Colet 2010; 15(Supl. 3):3523-3528.

Article submitted 22/10/2013

Approved 25/11/2013

Final version submitted 28/11/2013 